\title{
Haloperidol increases expression of the inositol 1,4,5-trisphosphate receptors in rat cardiac atria, but not in ventricles
}

\author{
Marie Novakova ${ }^{1}$, Barbora Sedlakova $^{2}$, Marta Sirova $^{2}$, Katerina Fialova ${ }^{1}$ and Olga Krizanova ${ }^{2}$ \\ 1 Department of Physiology, Faculty of Medicine, Masaryk University, Komenského nám. 2, Brno, Czech Republic \\ 2 Institute of Molecular Physiology and Genetics, Centre of Excellence for Cardiovascular Research, Slovak Academy \\ of Sciences, Vlárska 5, Bratislava, Slovakia
}

\begin{abstract}
Numerous ligands of sigma receptors are known to prolong the QT interval and therefore cause a variety of arrhythmias. High affinity binding sites for the prototypical sigma ligand haloperidol were found in membranes of cardiac myocytes from adult rats. Activation of sigma 1 receptor leads to a release of calcium from the endoplasmic reticulum that follows increased synthesis of inositol 1,4,5-trisphosphate $\left(\mathrm{IP}_{3}\right)$.

We studied the effect of long-term haloperidol treatment on the expression of sigma 1 receptors, $\mathrm{IP}_{3}$ receptors of type 1 and 2 in the individual parts of the rat heart, in isolated rat cardiomyocytes and in PC12 cells.

We have found that prolonged treatment with haloperidol significantly increased mRNA levels of sigma 1 receptors in both atria and ventricles. Sigma 1 receptor's mRNA was increased also in isolated cardiomyocytes. Haloperidol treatment affects the expression of $\mathrm{IP}_{3}$ receptors of type 1 and 2 in cardiac atria, but not in cardiac ventricles. We observed increase in $\mathrm{IP}_{3}$ receptors in differentiated PC12 cells, but not in isolated cardiomyocytes. We propose that this increase might participate in triggering cardiac arrhythmias during haloperidol treatment, which has to be further verified.
\end{abstract}

Key words: Haloperidol — Sigma 1 receptors — Inositol 1,4,5-trisphosphate receptors

\section{Introduction}

The previous generation of antidepressants and neuroleptics is known to be cardiotoxic. These drugs inhibit cardiovascular $\mathrm{Na}^{+}, \mathrm{Ca}^{2+}$, and $\mathrm{K}^{+}$channels leading to life-threatening arrhythmias (Pacher and Kecskemeti 2004). These arrhythmias are reflected as various changes in the electrocardiogram, quite frequently manifested as prolongation of QT interval. Lengthening of QT interval may be associated with a potentially life-threatening polymorphic ventricular tachyarrhythmia known as torsade de pointes (TdP; Welch and Chue 2000). It may be manifested as syncope and even sudden cardiac death, often preceded by ventricular fibrillation. QT prolongation can occur as congenital or acquired form,

Correspondence to: Olga Krizanova, Institute of Molecular Physiology and Genetics, Centre of Excellence for Cardiovascular Research, Slovak Academy of Sciences, Vlárska 5, 83334 Bratislava, Slovakia

E-mail: olga.krizanova@savba.sk the latter induced by various cardiac and non-cardiac drugs. Among antipsychotics, haloperidol, droperidol, pimozide, sertindole, and thioridazine were found to cause definitively acquired long QT syndrome (Henderson et al. 1991; Metzger and Friedman 1993; Krähenbühl et al. 1995; Barnett 1996; Pezawas et al. 2000; Glassman and Bigger 2001).

Haloperidol is the most potent neuroleptic agent which has been widely used not only in psychiatric patients but also in patients with other diagnoses, mainly in geriatric and surgical patients for the control of severe agitation, e.g. after general anesthesia. Haloperidol was considered to be a safe drug, but both individual case reports and small studies documented that it can prolong the corrected QT interval, cause TdP, and result in sudden cardiac death. These events can occur at normal therapeutic doses with either oral (Fayer 1986; Kriwisky et al. 1990) or intravenous (Hunt and Stern 1995) use and/or as a result of overdose (Henderson et al. 1991).

Sigma receptors have been recently identified as unique ligand-regulated molecular chaperones in the endoplasmic 
reticulum of various cells. They are involved in a variety of cardiovascular functions, such as the regulation of cardiac contractility and rhythm and the regulation of coronary and peripheral arterial vasomotor activity (Monassier and Bousquet 2002). Sigma receptors have been localized in several structures within the central nervous system as well as in peripheral tissues (heart, spleen, liver; Roman et al. 1989; Wolfe et al. 1989; Ela et al. 1994; Torrence-Campbell and Bowen 1996; Alonso et al. 2000). The sigma receptors modulate potassium (Nguyen et al. 1998), calcium (Church and Fletcher 1995) and sodium channels (Johannessen et al. 2009) and they are involved in the cellular pathways using $\mathrm{G}$ proteins (Tokuyama et al. 1997). According to recent studies the family of sigma receptors is subdivided into two groups: sigma 1 and sigma 2 receptors. These two receptors might in fact constitute two isoforms of the same protein. As they play a role in the regulation of the intracellular calcium stores, they are involved in the modulation of cardiac contractility. It is also very likely that they are involved in the control of arterial vasomotoric activity, probably through complex actions implying endothelial effects and some direct vasoconstrictive effects on smooth muscle cells, which would involve the same type of cellular pathways as in cardiomyocytes. High affinity binding sites for sigma receptor ligands were found in membranes of cardiac myocytes from adult rats. Exposure to $10 \mathrm{nM}$ haloperidol induced an increase in the amplitude of contraction; a lower concentration of haloperidol (1 nM) did not induce an increase in the contraction amplitude but rather reduced the amplitude (Novakova et al. 1995). Activation of sigma 1 receptor leads to a release of calcium from the endoplasmic reticulum that follows increased synthesis of inositol trisphosphate $\left(\mathrm{IP}_{3}\right)$ and is totally prevented by the blocker of phospholipase C, neomycin (Novakova et al. 1998). Signaling cascade of sigma receptors is dependent on $\mathrm{IP}_{3}$ receptors, since silencing of both - type 1 and $2 \mathrm{IP}_{3}$ receptors resulted in decreased mRNA levels of sigma receptors (Novakova et al. 2007). Fialova and coworkers (Fialova et al. 2009) examined the incidence of arrhythmias, changes in heart rate, and QT interval prolongation in isolated Langendorff-perfused rat and guinea pig hearts after they were exposed to nanomolar concentrations of haloperidol. While both, QT prolongation and arrhythmias due to haloperidol administration were observed in untreated rat and guinea pig hearts, arrhythmias were completely prevented in both species of chronically treated animals.

Based on the current knowledge we studied the effect of long-term haloperidol treatment on the expression of sigma 1 receptors, $\mathrm{IP}_{3}$ receptors of type 1 and 2 in the individual parts of the rat heart, in isolated rat cardiomyocytes and in PC12 cells. Moreover, rate-corrected QT interval has been evaluated in previously recorded electrograms of isolated hearts from haloperidol-untreated and treated rats.

\section{Materials and Methods}

\section{Animals}

Adult male Wistar rats, weighing 210-280 g were used in the study. Only males were included in the study, since sigma receptors are known to be modulated by progesterone. Prior to the experiment, the animals were housed for 1 week in a controlled environment $\left(22^{\circ} \mathrm{C} \pm 2{ }^{\circ} \mathrm{C}, 12 \mathrm{~h}\right.$ light/dark cycle, lights on at 6.00 a.m., humidity $45-55 \%)$. Food and water were available ad libitum. All animal experiments were carried out with respect to the recommendations of the European Community Guide for the Care and Use of Laboratory Animals and followed the guidelines for animal treatment approved by local authorities.

\section{PC12 cells}

PC12 cells derived from a rat pheochromocytoma were cultured in Minimal essential medium of Dulbecco (DMEM; Biochrom AG, Germany) with high glucose ( $4.5 \mathrm{~g} / \mathrm{l})$ supplemented with $15 \%$ fetal calf serum and antibiotics penicillin and streptomycin. PC12 cells were cultured in a water-saturated atmosphere at $37^{\circ} \mathrm{C}$ and $5 \%$ $\mathrm{CO}_{2}$. For differentiation, cells were plated onto poly-Llysine-coated 6-well plates or coverslips, treated with 100 $\mathrm{ng} / \mathrm{ml}$ Nerve growth factor- $\beta$ (NGF) and cultivated for 5 days at $37^{\circ} \mathrm{C}$ in $5 \% \mathrm{CO}_{2}$. Afterwards, differentiated cells were treated with haloperidol (in a final concentration 10 $\mathrm{nM}$ ) for 3 hours.

\section{Preparation of cardiomyocytes}

Male Wistar rats (220-270 g) were anaesthetized with pentobarbital (Spofa, Czech Republic), in the dose of $1020 \mathrm{mg} / 100 \mathrm{~g}$ of body weight, and heparin (Leciva, Czech Republic; $0.2 \mathrm{ml}$ ) was added. The heart was rapidly excised and placed into a cold Krebs solution $\left(5^{\circ} \mathrm{C}\right)$. The aorta was then cannulated and the heart perfused for 3-5 min with Krebs-Henseleit $(\mathrm{K}-\mathrm{H})$ solution $\left(37^{\circ} \mathrm{C}\right.$, $1.25 \mathrm{mM} \mathrm{CaCl}_{2}$, perfusion pressure $85 \mathrm{mmHg}$ ) to washout the blood and to stabilize the heart. All hearts exhibiting any arrhythmias in this phase were excluded from the experiment. After 3-5 min, perfusion was switched to calcium-free K-H solution for $5 \mathrm{~min}$ at the same conditions. Afterwards, the heart was perfused with Liberase Blendzyme 4 (Roche Diagnostics, Germany) in K-H solution for 10-20 $\mathrm{min}$. When the heart became swollen and turned slightly pale, the enzymatic digestion was stopped, atria were removed and the heart was placed in the Petri dish containing HEPES solution with $2 \%$ albumin (Bovine Albumin, Fraction V; Sigma-Aldrich, Czech Republic), minced with scissors and individual cardiomyocytes were 
obtained by gentle stirring at the pre-heated magnetic stirrer. The cell suspension was filtered through mull, placed into conical tube and centrifuged $(250 \mathrm{rev} / \mathrm{min})$. The supernatant was then removed, myocytes resuspended in albumin-free HEPES and calcium added to the final concentration of $0.4 \mathrm{mM}$.

\section{Chronic administration of haloperidol}

Seven rats included in treated group (chronic group) were kept in certified Animal Facility of the Faculty of Medicine and fed by standard diet ad libitum. They were given intraperitoneal injection of haloperidol ( $2 \mathrm{mg} / \mathrm{kg}$ of body mass) once a day, in the morning hours, for 21 consecutive days. Haloperidol (Sigma-Aldrich, Czech Republic) was prepared as stock solution of final concentration $4 \cdot 10^{-4} \mathrm{M}$. The proper dose of the substance was daily calculated for each animal according to its actual body mass; the volume of stock solution injected per animal and day never exceeded $5 \mathrm{ml}$. Three rats (control group) were treated with physiological solution according to the same experimental protocol. Next day after the last injection, the animals were taken into the experiment. The chest of rat was always opened under deep anesthesia, its heart was quickly excised and dissected into four parts - left and right atria and left and right ventricles, respectively. The samples were stored at $-80^{\circ} \mathrm{C}$ until processed.

\section{Isolated heart preparation and rate-corrected $\mathrm{QT}$ interval evaluation}

According to the same protocol, the hearts of chronically haloperidol-treated rats were prepared in our previous study (Fialova et al. 2009). They were compared with the hearts of rats, which did not obtain any treatment prior to isolation and perfusion at Langendorff set-up. Briefly, the animals from any group were sacrificed under deep anesthesia. Their chest was opened, the heart quickly excised and the aorta cannulated. The heart was then perfused at modified Langendorff apparatus at constant perfusion pressure (85 $\mathrm{mmHg}$ ) with $\mathrm{K}-\mathrm{H}$ solution containing (in $\mathrm{mM}$ ): $118 \mathrm{NaCl}$, $4.7 \mathrm{KCl}, 25.0 \mathrm{NaHCO}_{3}, 7.0$ glucose, $1.2 \mathrm{KH}_{2} \mathrm{PO}_{4}, 1.2 \mathrm{MgSO}_{4}$ and $1.25 \mathrm{CaCl}_{2}$. The solution was bubbled with a mixture of $95 \% \mathrm{O}_{2}$ and $5 \% \mathrm{CO}_{2}$ and maintained at $37^{\circ} \mathrm{C}$ throughout the experiment. The heart was placed in a thermostaticallycontrolled bath filled with $\mathrm{K}-\mathrm{H}$ solution. The temperature gradient between perfusion and bath solutions did not exceed $0.5^{\circ} \mathrm{C}$. The hearts were allowed to beat spontaneously. The quality of each preparation was evaluated at the end of control period - 30 min perfusion with K-H solution (steady state heart rate and no arrhythmias).

The experiment consisted of four 30 min periods: control period, $10 \mathrm{nM}$ haloperidol administration, washout period, and the second $10 \mathrm{nM}$ haloperidol application. During the whole experiment, electrograms were continually recorded from three orthogonal bipolar leads (X, Y, and Z) by the touch-free method. Six silver-silver chloride disc electrodes ( $4 \mathrm{~mm}$ in diameter) were placed on the inner surface of the bath in which the heart was placed during the experiment. The electrograms were amplified by a set of three biological amplifiers DAM50 (World Precision Instruments, USA) and further simultaneously digitized by 16 -bit $\mathrm{AD}$ converters at rate of 2000 samples/s using a data acquisition multifunction card PCI-6250 (National Instruments, USA). The acquisition card also provides pre-amplification of the signals and their filtering by anti-aliasing filters. The digital signals are stored on a hard disk for further off-line processing (noise suppression, visualization and analysis). Data acquisition is controlled by subroutines of a software package LabView (National Instruments, USA). The recorded electrograms were stored and subsequently analyzed - heart rate, QT interval changes and incidence of arrhythmias were evaluated.

For the present study, QT interval as an indicator of arrhythmias risk was studied in more detail. Ten successive QT intervals were averaged at the end of control period; this average QT interval was used for normalization of data in next phases of experiment. In order to exclude putative effect of observed heart rate changes in chronically treated animals (Fialova et al. 2009), in this study all measured values of $\mathrm{QT}$ interval were corrected to particular heart rate and expressed as rate-corrected QT (QTc). For correction, the formula according to Kawataki was used (Malik and Camm 1996).

\section{$R N A$ preparation and quantification of relative $m R N A$ levels by RT-PCR}

Total RNA from tissues and from PC12 cells was isolated with TRI Reagent (MRC, USA). Briefly, tissue samples were homogenized with a tissue homogenizer (BioSpec Products, USA), in TRI Reagent (PC12 cells were homogenized by pipette tip in sterile water and afterwards TRI Reagent was added) and after 5 min the homogenate was extracted with chloroform. RNAs in the aqueous phase were precipitated by isopropanol. The RNA pellet was washed with $75 \%$ ethanol and stored in $96 \%$ ethanol at $-70^{\circ} \mathrm{C}$. The purity and concentration of isolated RNA was checked with a GeneQuant Pro spectrophotometer (Amersham Biosciences, UK) at $260 \mathrm{~nm}, 260 / 280 \mathrm{~nm}$ and $230 / 260 \mathrm{~nm}$, respectively. Reverse transcription was performed using $1.5 \mu \mathrm{g}$ of total RNAs and Ready-To-Go YouPrime First-Strand Beads with $\mathrm{pd}(\mathrm{N})_{6}$ primer (both from GE Healthcare-Life Sciences, UK). PCRs specific for the type 1 and $2 \mathrm{IP}_{3}$ receptors (IP3R1 and IP3R2) and for the sigma 1 receptor (SIG1R) were carried out using appropri- 
Table 1. Primers used in RT-PCR

\begin{tabular}{|c|c|c|c|}
\hline Primer & Sequence & GI & Fragment \\
\hline IP3R1 & 5'- GTG GAG GTT TCA TCT GCA AGC -3‘ & 1054962 & $410 \mathrm{bp}$ \\
\hline IP3R2 & 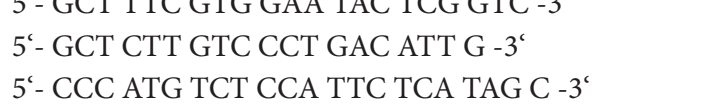 & 34851153 & $361 \mathrm{bp}$ \\
\hline SIG1R & $\begin{array}{l}\text { 5'- GAG GCA ACA GCT GTG GAG TG -3‘ } \\
5^{`} \text { - AAA GAG GTA GGT GGT GAG CTC -3‘ }\end{array}$ & 38541100 & 185 bp \\
\hline CYCLO & $\begin{array}{l}\text { 5'- CGT GCT CTG AGC ACT GGG GAG AAA - } 3^{‘} \\
5^{‘} \text { - CAT GCC TTC TTT CAC CTT CCC AAA GAC - } 3^{\star}\end{array}$ & 203701 & 300 bp \\
\hline
\end{tabular}

IP3R1, IP3R2, inositol trisphosphate receptors type 1 and 2; Sig1R sigma 1 receptor; CYCLO, cyclophilin A.

ate primers (Table 1). Cyclophilin A (CYCLO) was used as a housekeeper gene control for semiquantitative evaluation of PCR. Each PCR program started with initial denaturation at $94^{\circ} \mathrm{C}$ for $5 \mathrm{~min}$, followed by 27 (for IP3R1, IP3R2, and SIG1) and 22 (for CYCLO) cycles of denaturation at $94^{\circ} \mathrm{C}$ for $1 \mathrm{~min}$, annealing at $60^{\circ} \mathrm{C}$ (for IP3R1, IP3R2, and $\mathrm{CYCLO}$ ) and at $65^{\circ} \mathrm{C}$ (for SIG1) for $1 \mathrm{~min}$, and polymerization at $72^{\circ} \mathrm{C}$ for $1 \mathrm{~min}$. PCRs were terminated by final polymerization at $72^{\circ} \mathrm{C}$ for $7 \mathrm{~min}$. All PCR products were analyzed on $2 \%$ agarose gels. Intensity of individual bands was evaluated by measuring the optical density per $\mathrm{mm}^{2}$ and compared relative to CYCLO mRNA.

\section{Western blot analysis}

IP3R1 and IP3R2 proteins were determined in crude membrane fraction from the rat atria and ventricles, and from the differentiated PC12 cells. Protein concentration was determined according to Lowry et al. (1951). Fifty micrograms of protein extract from tissue sample, resp. one hundred micrograms of protein extract from cells was separated by electrophoresis on $6 \%$ SDS polyacrylamide gels and proteins were transferred to Hybond ECL membrane using semidry blotting (Owl Separation Systems, USA). Membrane was blocked in 5\% non-fat dry milk diluted in TBST (Tris buffered saline-Tween) and then incubated with appropriate antibody. For the detection of IP3R1 from tissue samples, rabbit antiIP3R1 polyclonal antibody (Chemicon-Millipore, USA) was utilized in dilution $1: 1000$. This antibody recognizes IP3R1. The epitope does not share homology with any other known protein. It reacts with rat and mouse. It is expected that the antibody will also react with human due to identical sequence homology. Other species have not been tested. For the detection of IP3R1 from cell samples, rabbit anti-IP3R1 polyclonal antibody (Calbiochem-Merck, Germany) was utilized in dilution $1: 1000$. This antibody recognizes the $240 \mathrm{kDa}$ monomeric $\mathrm{IP}_{3}$ receptor protein. It reacts with rat, mouse, canine and human. For the detection of IP3R2, rabbit anti-
IP3R2 polyclonal antibody (Chemicon International, USA) diluted $1: 1000$ was used. The antibody recognizes $250 \mathrm{kDa}$ IP3R2 protein. It reacts with human and mouse. Reactivity with other species has not been determined. It is expected that the antibody will also react with rat and canine.

Horseradish peroxidase linked secondary antibody and enhanced chemiluminescence was used for visualization. Signal was detected on Kodak camera. Optical density of individual bands was quantified using PCBAS 2.08e software.

\section{Statistical analysis}

Each value represents the average of 3-7 animals, or 3 individual cultivations in three independent wells (PC12 cells). Electrograms from 11 animals were included in each tested group. Results are presented as mean \pm S.E.M. Statistical differences among groups were determined by $t$-test and paired $t$-test (QTc). Statistical significance $p<0.05$ was considered significant.

\section{Results}

Treatment of rats with haloperidol resulted in significant increase of the mRNA levels of the sigma 1 receptors in both atria and ventricles (Fig. 1). After haloperidol treatment, the mRNA level of the sigma 1 receptors in all tested parts of the rat heart was increased approximately two-fold.

The mRNA levels of the IP3R1 in both, left and right rat heart atrium of haloperidol-treated rats were significantly increased (Fig. 2A). In both atria, the IP3R1 mRNA increased approximately two-fold. Protein levels of the IP3R1 in atria of rats after haloperidol treatment were also significantly elevated (Fig. 2B). On the contrary, the mRNA (Fig. 2A) levels of the IP3R1 in both ventricles were not significantly different in the control group and the group of haloperidoltreated rats. Protein (Fig. 2B) levels of the IP3R1 in ventricles of haloperidol-treated rats were not changed as well. 
After haloperidol treatment, the mRNA levels of the IP3R2 were significantly elevated in both atria (Fig. 3A). In the left and right atrium, the same increase of the mRNA levels of the IP3R2 was observed. The protein levels of the IP3R2 in rat atria after haloperidol treatment were also significantly increased (Fig. 3B). While in both, left and right ventricles of haloperidol - treated rats the mRNA levels of the IP3R2 were not changed (Fig. 3A), the protein levels of the IP3R2 in ventricles were decreased (Fig. 3B).

In order to determine, whether haloperidol induced up-regulation of IP3R1 and IP3R2 in cardiomyocytes or in neuronal cells, we measured gene expression of sigma 1 receptors and IP3R2 receptors in isolated left ventricular cardiomyocytes (Fig. 4A), and in differentiated PC12 cells (Fig. 4B). Differentiated PC12 cells are considered to be a convenient model of neuronal cells. Sigma 1 receptor mRNA was increased also in isolated cardiomyocytes (Fig. 4A), but mRNA levels of IP3R2 (which are known to be expressed in cardiomyocytes) were not changed as compared to control cardiomyocytes. Treatment of PC12 cells with haloperidol resulted in significant increase of the mRNA (Fig. 4B) levels of both types of the $\mathrm{IP}_{3}$ receptors, IP3R1 and IP3R2. The mRNA levels of the IP3R2 in PC12 cells after haloperidol treatment were elevated approximately two-fold, the mRNA levels of the IP3R1 in PC12 cells were increased only a one half after haloperidol treatment.

Rate-corrected QT interval did not differ at control conditions between the hearts from untreated (acute) and treated (chronic) rats. In acute group, QTc significantly lengthened after the first haloperidol administration and this prolongation was significantly reversible during washout period. The
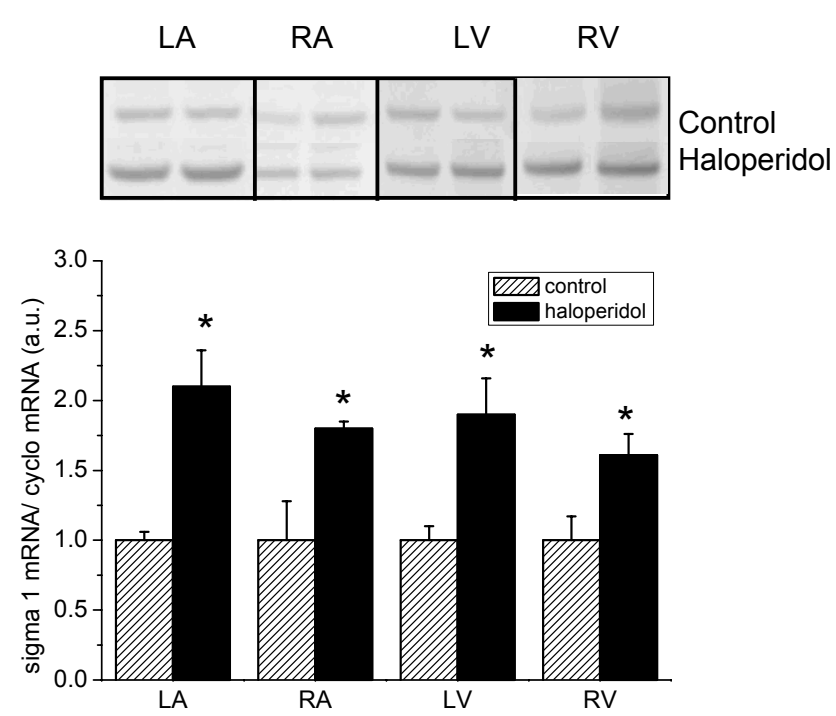

Figure 1. The mRNA levels of the sigma 1 receptors in left atrium (LA), in right atrium (RA), in left ventricle (LV), and in right ventricle (RV). Sigma 1 receptors mRNA was quantified relatively to the housekeeper CYCLO. Control, untreated animals; Haloperidol, animals treated for 21 days with haloperidol. Each column is displayed as mean \pm S.E.M. and represent an average of 3-7 animals. Statistical significance calculated by $t$-test represents ${ }^{\star} p<0.05$.

second haloperidol administration did not cause any further significant change. In the group of treated hearts, similar changes were observed: significant QTc prolongation after the first haloperidol dose, which was not fully washable and surprisingly the second haloperidol application causing significant prolongation of rate-corrected QT interval.
A

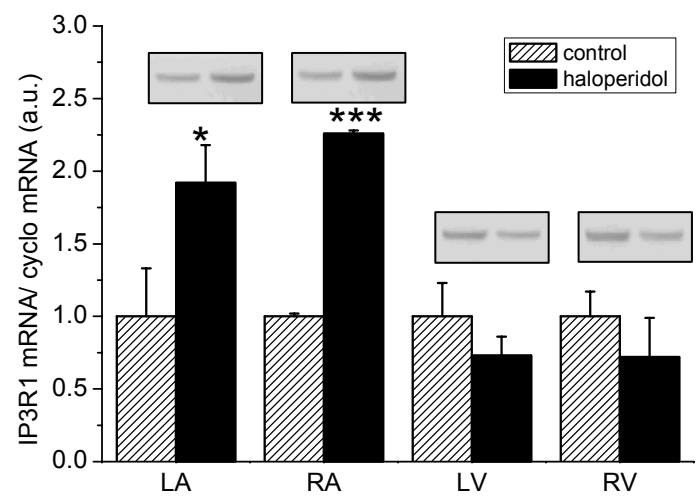

B

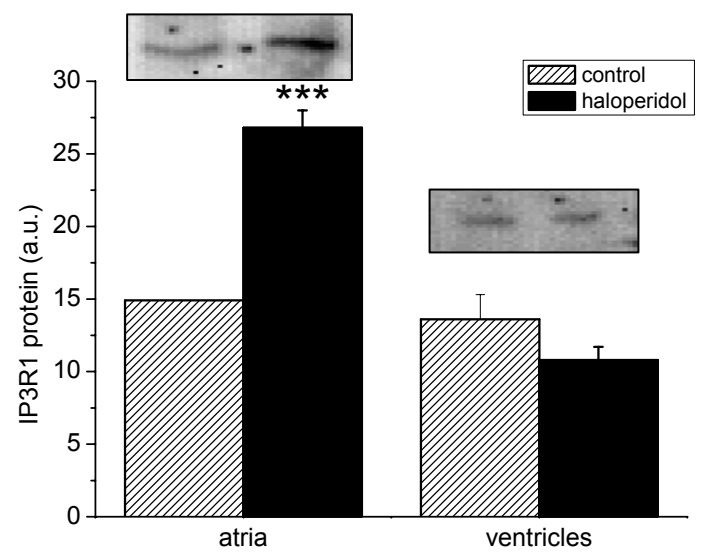

Figure 2. The mRNA (A) and protein (B) levels of the IP3R1 in left atrium (LA), in right atrium (RA), in left ventricle (LV), and in right ventricle (RV). IP3R1 mRNA was quantified relatively to the housekeeper CYCLO. Control, untreated animals; Haloperidol, animals treated for 21 days with haloperidol. Each column is displayed as mean \pm S.E.M. and represent an average of 3-7 animals. Statistical significance calculated by $t$-test represents ${ }^{\star} p<0.05 ;{ }^{\star * *} p<0.001$. 
A

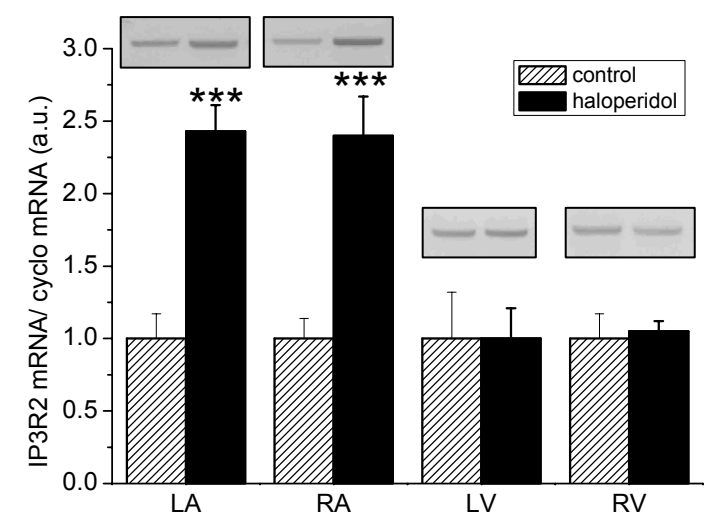

B

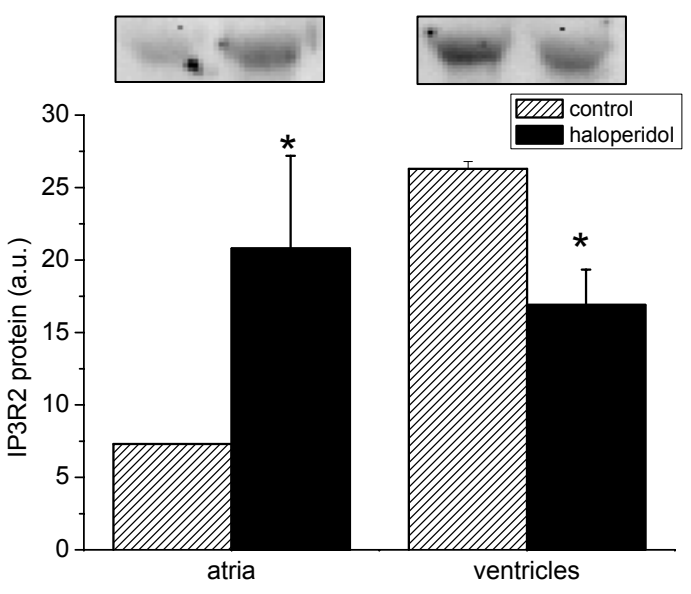

Figure 3. The mRNA (A) and protein (B) levels of the IP3R2 in left atrium (LA), in right atrium (RA), in left ventricle (LV), and in right ventricle (RV). IP3R2 mRNA was quantified relatively to the housekeeper CYCLO. Control, untreated animals; Haloperidol, animals treated for 21 days with haloperidol. Each column is displayed as mean \pm S.E.M. and represent an average of 3-7 animals. Statistical significance calculated by $t$-test represents ${ }^{\star} p<0.05 ;{ }^{\star * \star} p<0.001$.

When QTc was compared between the two groups of hearts, significant difference was found after the first haloperidol application and in washout, insignificant prolongation in the second haloperidol period (Fig. 5).

\section{Discussion}

We have found that prolonged treatment with haloperidol significantly increased mRNA levels of sigma 1 receptors in cardiac atria and ventricles. Sigma 1 receptor has recently been identified as a unique ligand-regulated molecular chaperone in the endoplasmic reticulum of cells (Maurice and $\mathrm{Su} 2009$ ). One of the most prominent actions of these receptors is the regulation of $\mathrm{IP}_{3}$ receptors. In our previous paper (Novakova et al. 2007) we have found that silencing of both, IP3R1 and IP3R2 results in decrease of sigma 1 receptor mRNA, suggesting the mutual direct or indirect interaction of these receptors. Here we have clearly shown that haloperidol significantly increased IP3R1 and IP3R2
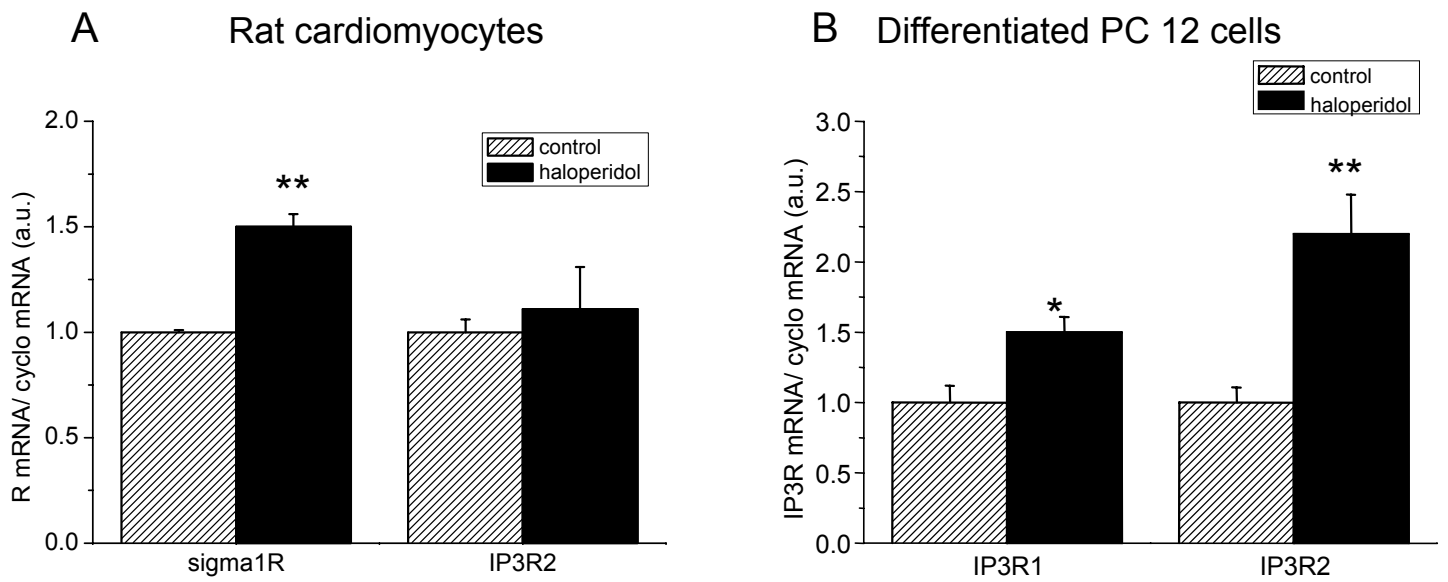

Figure 4. The mRNA levels of the sigma 1 receptors and of the IP3R2 in isolated left ventricular cardiomyocytes (R-receptor; A) and the mRNA levels of the IP3R1 and IP3R2 in PC12 cells (B). Sigma 1 receptors, IP3R1, and IP3R2 mRNA was quantified relatively to the housekeeper CYCLO. Control, untreated animals and/or cells; Haloperidol, animals and/or cells treated with haloperidol. Each column is displayed as mean \pm S.E.M. and represent an average of 3-7 animals and/or plate wells. Statistical significance calculated by $t$-test represents ${ }^{\star} p<0.05 ;{ }^{* *} p<0.01$. 


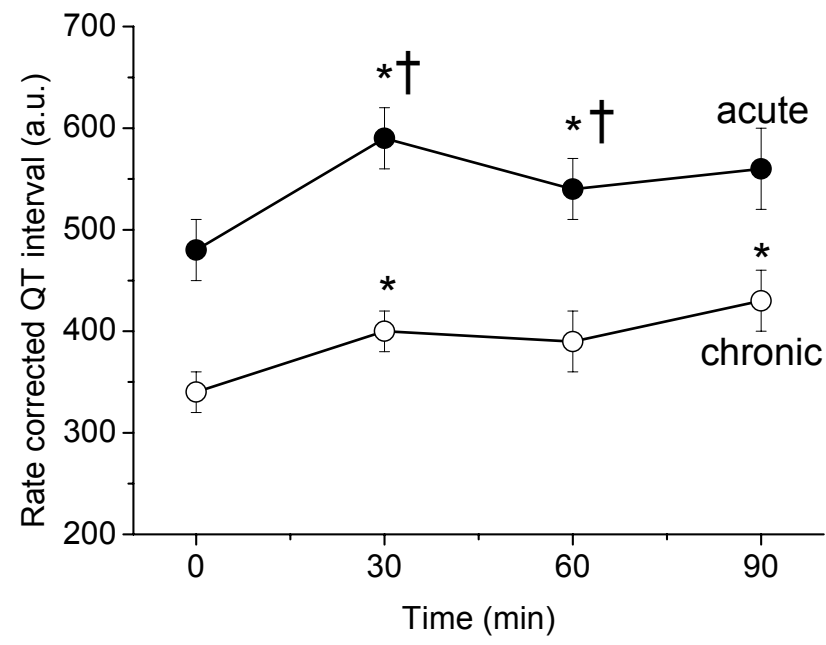

Figure 5. Comparison of rate-corrected QT interval in isolated hearts from non-treated (acute) and haloperidol-treated (chronic) rats. ${ }^{\star} p<0.05$ represents significant change between two consecutive phases of experiment; $\dagger p<0.05$ represents the significant change between the same phase in both groups.

in cardiac atria, but not in ventricles on both, mRNA and protein level. Since atria are much more innervated and cardiac ganglia are localized in both, left and right atrium, we propose that haloperidol-induced increase in $\mathrm{IP}_{3}$ receptors occurs predominantly in neuronal cells. To verify this hypothesis we tested the effect of haloperidol on isolated ventricular cardiomyocytes and on differentiated PC12 cells. PC12 cells have been widely used as a model system for NGF-induced neuronal differentiation and these cells have sigma 1 receptors (Takebayashi et al. 2002; 2004). In accordance with our proposal we observed increase in $\mathrm{IP}_{3}$ receptors in differentiated $\mathrm{PC} 12$ cells, but not in isolated cardiomyocytes.

Sigma 1 receptors have been shown to affect intracellular calcium signaling, although the precise molecular and cellular mechanisms are unknown. It has been reported that sigma 1 receptors bind to $\mathrm{IP}_{3}$ receptors in the endoplasmic reticulum (Hayashi and $\mathrm{Su}$ 2001). Ishima and colleagues (Ishima et al. 2008) showed that both sigma 1 receptors and $\mathrm{IP}_{3}$ receptors are involved in the potentiation of NGFinduced neurite outgrowth by acetylcholinesterase inhibitor donepezil, which is known to bind to sigma 1 receptors in the brain. Accumulating evidence suggests that sigma 1 receptors are involved in both neuroplasticity and pathophysiology of neuropsychiatric diseases such as major depressive disorders, anxiety, schizophrenia and Alzheimer's disease (Hayashi and Su 2004; Takebayashi et al. 2004; Bermack and Debonnel 2005). Sigma 1 receptors form a trimeric complex with two other proteins on the endoplasmic reticulum: $\mathrm{IP}_{3}$ receptor and the ankyrin isomer $220 . \mathrm{IP}_{3}$ receptors as the intracellular calcium channels participate on the calcium release from the endoplasmic reticulum. Both, type 1 and $2 \mathrm{IP}_{3}$ receptors were found in the heart, with higher prevalence of IP3R2 in cardiomyocytes and IP3R1 in cardiac ganglia (Krizanova et al. 2008). These receptors are proposed to indirectly modulate the process of excitation-contraction coupling in the heart and to be involved in development of the pathophysiological state of the heart. Also, cellular defects in ankyrin-based ion channels and transporter targeting pathways have previously been linked with abnormal vertebrate physiology and human diseases. Isolated sinoatrial node (SAN) cells from ankyrinB-deficient animals displayed abnormal membrane expression of $\mathrm{Na}^{+} / \mathrm{Ca}^{2+}$ exchanger, $\mathrm{Na}^{+} / \mathrm{K}^{+}$ATPase, $\mathrm{IP}_{3}$ receptor and surprisingly, $\mathrm{Ca}_{\mathrm{V}}$ 1.3. Loss of ankyrin-B promoted slow and irregular $\mathrm{Ca}^{2+}$ release, as well as afterdepolarizations in isolated SAN cells. Therefore, ankyrin-based pathways may serve as ideal therapeutic targets in SAN cardiomyocytes where a "multi-hit" approach is necessary to impact a complex process such as SAN cell automaticity (Hund and Mohler 2008). Taken together, haloperidol possesses the most harmful effect on cardiac ganglia, where it increases expression of sigma 1 receptors and also type 1 and $2 \mathrm{IP}_{3}$ receptors, which might consequently alter calcium signaling and affect excitation-contraction process.

QT interval changes are believed to be closely related to arrhythmias appearance. Thus, the main role of QT interval monitoring is identification of warning signs that precede torsade de pointes and eventually sudden cardiac death. In our previous study (Fialova et al. 2009) chronic treatment of rats with haloperidol completely abolished the arrhythmias in their isolated hearts exposed to another dose of haloperidol distributed in perfusion solution at Langendorff set-up. However, QT interval changes did not completely correspond to this finding as might be expected - the first haloperidol application still caused significant prolongation of QT interval in chronic rats, although less pronounced than in case of acute, non-treated animals. The second exposure to haloperidol in chronic animal hearts already did not cause any significant change of QT interval. Since the normalized heart rate of untreated rat isolated hearts did not show any change and those of the chronically treated rats showed significant steady decay during the whole experiment, we proposed that the QT interval might be affected by these heart rate changes. Thus, in the present study, the QT interval was corrected to the actual heart rate for each studied heart. The formula, which has been chosen, reflects best from all available ones the heart rate values at which the hearts were beating.

Rate-corrected QT interval did not differ at control conditions between the two tested groups. However, similar changes of rate-corrected QT interval were observed as in case of non-corrected QT interval (Fialova et al. 2009) - significant QTc prolongation after the first, and insignificant or at least much less expressed QTc prolongation after the 
second haloperidol application. So far we did not prove the direct link between the QTc interval changes and arrhythmias occurrence in our model. When QTc was compared between the acute and chronic hearts, significant difference was found after the first haloperidol application and in washout, insignificant prolongation in the second haloperidol period (Fig. 5). Thus, the rather surprising significant prolongation of rate-corrected QT interval after the second haloperidol application may be ignored.

Since the heart rate differed between acute and chronic rat groups, we may assume that conductive system and/or the ability of spontaneous action potential triggering by this system is affected by chronic treatment with haloperidol. This is in accordance with our finding of up-regulation of $\mathrm{IP}_{3}$ receptors and down-regulation of sigma 1 receptors in neuronal cells of atria which we present in this paper. The heart rate represents one of important parameters which affect cardiac contractility; therefore we may suppose that close relationship between sigma receptor, $\mathrm{IP}_{3}$ receptor and ankyrin 220 and the ability of this trimeric complex to chaperone certain ionic specific channels on cardiomyocyte, represents phylogenetically old system of fine modulation of cardiac contractility based on affecting of calcium fluxes among various compartments in the cardiac cell.

\section{Conclusions}

In summary, we have found that haloperidol treatment affects the expression of IP3R1 and IP3R2 in cardiac atria, but not in cardiac ventricles. This increase is due to up-regulation of genes for these receptors in neuronal cells rather than in cardiomyocytes. We propose that this increase might participate in triggering cardiac arrhytmias during haloperidol treatment, which has to be further verified.

Acknowledgement. This work was supported by grants VEGA 2/0049/10, APVV 51/0397 and partially by grants GACR 102/07/ 1473 and MSM0021622402.

\section{References}

Alonso G., Phan V., Guillemain I., Saunier M., Legrand A., Anoal M., Maurice T. (2000): Immunocytochemical localization of the sigma(1) receptor in the adult rat central nervous system. Neuroscience 97, 155-170; doi:10.1016/S03064522(00)00014-2

Barnett A. A. (1996): Safety concerens over antipsychotic drug, sertindole. Lancet 348, 256-257; doi:10.1016/S01406736(05)65549-3

Bermack J. E., Debonnel G. (2005): The role of sigma receptors in depression. J. Pharmacol. Sci. 97, 317-336; doi:10.1254/ jphs.CRJ04005X
Church J., Fletcher E. J.(1995): Blockade by sigma site ligands of high voltage-activated $\mathrm{Ca}^{2+}$ channels in rat and mouse cultured hippocampal pyramidal neurones. Br. J. Pharmacol. 116, 2801-2810

Ela C., Barg J., Vogel Z., Hasin Y., Eilam Y. (1994): Sigma receptor ligands modulate contractility, $\mathrm{Ca}^{2+}$ influx and beating rate in cultured cardiac myocytes. J. Pharmacol. Exp. Ther. 269, 1300-1309

Fayer S. A. (1986): Torsades de pointes ventricular tachyarrhythmia associated with haloperidol. J. Clin. Psychopharmacol. 6, 375-376; doi:10.1097/00004714-198612000-00018

Fialova K., Krizanova O., Jarkovsky J., Novakova M. (2009): Apparent desensitization of the effects of sigma receptor ligand haloperidol in isolated rat and guinea pig hearts after chronic treatment. Can. J. Physiol. Pharmacol. 87, 1019-1027; doi:10.1139/Y09-066

Glassman A. H., Bigger J. T. Jr. (2001): Antipsychotic drugs: prolonged QTc interval, torsade de pointes, and sudden death. Am. J. Psychiatry 158, 1774-1782; doi:10.1176/ appi.ajp.158.11.1774

Henderson R. A., Lane S., Henry J. A. (1991): Life-threatening ventricular arrhythmia (torsades de pointes) after haloperidol overdose. Hum. Exp. Toxicol. 10, 59-62; doi:10.1177/096032719101000110

Hayashi T., Su T. P. (2001): Regulating ankyrin dynamics: Roles of sigma-1 receptors. Proc. Natl. Acad. Sci. U.S.A. 98, 491-496; doi:10.1073/pnas.021413698

Hayashi T., Su T. P. (2004): Sigma-1 receptor ligands: potential in the treatment of neuropsychiatric disorders. CNS Drugs 18, 269-284; doi:10.2165/00023210-200418050-00001

Hund T. J., Mohler P. J. (2008): Ankyrin-based targeting pathway regulates human sinoatrial node automaticity. Channels (Austin) 2, 404-406; doi:10.4161/chan.2.6.7220

Hunt N., Stern T. A. (1995): The association between intravenous haloperidol and Torsades de Pointes. Three cases and a literature review. Psychosomatics 36, 541-549

Ishima T., Nishimura T., Iyo M., Hashimoto K. (2008): Potentiation of nerve growth factor-induced neurite outgrowth in PC12 cells by donepezil: role of sigma-1 receptors and IP3 receptors. Prog. Neuropsychopharmacol. Biol. Psychiatry 32, 1656-1659; doi:10.1016/j.pnpbp.2008.06.011

Johannessen M., Ramachandran S., Reamer L., Ramos-Serrano A., Ruoho A. E., Jackson M. B. (2009): Voltage-gated sodium channel modulation by sigma-receptors in cardiac myocytes and heterologous systems. Am. J. Physiol. Cell. Physiol. 296, C1049-1057; doi:10.1152/ajpcell.00431.2008

Krähenbühl S., Sauter B., Kupferschmidt H., Krause M., Wyss P. A., Meier P. J. (1995): Case report: reversible QT prolongation with torsades de pointes in a patient with pimozide intoxication. Am. J. Med. Sci. 309, 315-316; doi:10.1097/00000441-199506000-00003

Kriwisky M., Perry G. Y., Tarchitsky D., Gutman Y., Kishon Y. (1990): Haloperidol-induced torsades de pointes. Chest 98, 482-484; doi:10.1378/chest.98.2.482

Krizanova O., Holotnakova T., Jurkovicova D., Polakova E., Zahradnikova A., Lacinova L., Kvetnanský R., Myslivecek J., Pastorekova S. (2008): Type 1 and 2 IP3 receptors respond 
differently to catecholamines and stress. Ann. N.Y. Acad. Sci. 1148, 331-337; doi:10.1196/annals.1410.023

Lowry O. H., Rosebrough N. J., Farr A. L., Randall R. J. (1951): Protein measurement with the Folin phenol reagent. J. Biol. Chem. 193, 265-275

Malik M., Camm A. J. (1996): Correct the QT interval correctly: Should QTc be expressed in the same units as the QT interval? Pacing. Clin. Electrophysiol. 19, 1531-1534; doi:10.1111/j.1540-8159.1996.tb03176.x

Maurice T., Su T. P. (2009): The pharmacology of sigma-1 receptors. Pharmacol. Ther. 124, 195-206; doi:10.1016/j.pharmthera.2009.07.001

Metzger E., Friedman R. (1993): Prolongation of the corrected QT and torsades de pointes cardiac arrhythmia associated with intravenous haloperidol in the medically ill. J. Clin. Psychopharmacol. 13, 128-132; doi:10.1097/00004714199304000-00007

Monassier L., Bousquet P. (2002): Sigma receptors: from discovery to highlights of their implications in the cardiovascular system. Fundam. Clin. Pharmacol. 16, 1-8; doi:10.1046/ j.1472-8206.2002.00063.x

Nguyen V. H., Ingram S. L., Kassiou M., Christie M. J. (1998): Sigma-binding site ligands inhibit $\mathrm{K}+$ currents in rat locus coeruleus neurons in vitro. Eur. J. Pharmacol. 361, 157-163; doi:10.1016/S0014-2999(98)00706-7

Novakova M., Ela C., Barg J., Vogel Z., Hasin Y., Eilam Y. (1995): Inotropic action of sigma receptor ligands in isolated cardiac myocytes from adult rats. Eur. J. Pharmacol. 286, 19-30; doi:10.1016/0014-2999(95)00424-J

Novakova M., Ela C., Bowen W. D., Hasin Y., Eilam Y. (1998): Highly selective sigma receptor ligands elevate inositol 1,4,5-trisphosphate production in rat cardiac myocytes. Eur. J. Pharmacol. 353, 315-327; doi:10.1016/S00142999(98)00398-7

Novakova M., Bruderova V., Sulova Z., Kopacek J., Lacinova L., Kvetnansky R., Vasku A., Kaplan P., Krizanova O., Jurkovicova D. (2007): Modulation of expression of the sigma receptors in the heart of rat and mouse in normal and pathological conditions. Gen. Physiol. Biophys. 26, $110-117$
Pacher P., Kecskemeti V. (2004): Cardiovascular side effects of new antidepressants and antipsychotics: new drugs, old concerns? Curr. Pharm. Des. 10, 2463-2475; doi:10.2174/ 1381612043383872

Pezawas L., Quiner S., Moertl D., Tauscher J., Barnas C., Küfferle B., Wolf R., Kasper S. (2000): Efficacy, cardiac safety and tolerability of sertindole: a drug surveillance. Int. Clin. Psychopharmacol. 15, 207-214; doi:10.1097/00004850200015040-00003

Roman F., Pascaud X., Chomette G., Bueno L., Junien J. L. (1989): Autoradiographic localization of sigma opioid receptors in the gastrointestinal tract of the guinea pig. Gastroenterology $97,76-82$

Takebayashi M., Hayashi T., Su T. P. (2002): Nerve growth factorinduced neurite sprouting in PC12 cells involves sigma-1 receptors: implications for antidepressants. J. Pharmacol. Exp. Ther. 303, 1227-1237; doi:10.1124/jpet.102.041970

Takebayashi M., Hayashi T., Su T. P. (2004): Sigma-1 receptors potentiate epidermal growth factor signaling towards neuritogenesis in PC12 cells: potential relation to lipid raft reconstitution. Synapse 53, 90-103; doi:10.1002/syn.20041

Tokuyama S., Hirata K., Ide A., Ueda H. (1997): Sigma ligands stimulate GTPase activity in mouse prefrontal membranes: evidence for the existence of metabotropic sigma receptor. Neurosci. Lett. 233, 141-144; doi:10.1016/ S0304-3940(97)00657-5

Torrence-Campbell C., Bowen W. D. (1996): Differential solubilization of rat liver sigma 1 and sigma 2 receptors: retention of sigma 2 sites in particulate fractions. Eur. J. Pharmacol. 304, 201-210; doi:10.1016/0014-2999(96)00109-4

Welch R., Chue P. (2000): Antipsychotic agents and QT changes. J. Psychiatry. Neurosci. 25, 154-160

Wolfe S. A. Jr., Culp S. G., De Souza E. B. (1989): Sigma-receptors in endocrine organs: identification, characterization, and autoradiographic localization in rat pituitary, adrenal, testis, and ovary. Endocrinology 124, 1160-1172; doi:10.1210/ endo-124-3-1160

Received: September 9, 2010

Final version accepted: October 22, 2010 